\title{
Interactive Strategy Optimizing the Attraction of Physical Activities for Teenagers According to Gender
}

\author{
Chawki Derbali $^{1, *}$, Fathi Matoussi² \& Ali Elloumi ${ }^{3}$ \\ ${ }^{1}$ University of Jendouba, Tunisia \\ ${ }^{2}$ Virtual University of Tunis, Tunisia \\ ${ }^{3}$ Laboratory TEC, University of Paris Descartes, France \\ *Correspondence: University of Jendouba, HIPES - Kef, Tunisia. Tel: 216-96-537-981. E-mail: \\ derbali_chawki@yahoo.fr
}

Received: June 17, 2019 Accepted: July 17, 2019 Online Published: July 23, 2019

doi:10.5430/wjss.v6n2p34 URL: https://doi.org/10.5430/wjss.v6n2p34

\begin{abstract}
This aim of this research is to explore and analyze to what extent the strategies to which physical education didactics in Tunisia contributed to address the duplication of gender stereotypes. A typical approach with binary choice regression was applied to analyze data obtained from questionnaires completed by 1326 adolescent students (724 girls and 602 boys) from Tunisia. Results relieved that sport opportunities are limited by the separate expectations of males and females in physical education and sport settings. The analysis reveals that gender stereotypes affect girls' sports activities and that is particularly true for sports suitable for boys. The effect of the appropriated stereotype was significantly higher for sports practices perceived as masculine. The research ends with imminent based on the distinction between gender skills and gender interest and implications for sport activities in order to enhance participation, enjoyment, and wellbeing of people in physical education and sport activities. Hence, the need to develop an internal logic of practice of sports activities by repeating individual and sexual differences.
\end{abstract}

Keywords: gender sports, individual differences, internal logic, inequality, ability

\section{Introduction}

The exploration of physical activities attraction and sports of the gender remains a fertile area of investigation. In several societies sport is observed as a masculine domain, and exceeds the female capability. Despite, the increased participation opportunity held to girls and women in sport the growth and popularity of women's sport, female athletes are considered inferior to male athletes that her body remains obsessed rather than her skills and they are underrepresented in leadership positions at much levels of sport (Burton, 2015; Trolan, 2013). Inequality in sport will continue to exist until society evolves its representation to female athletes. The socialization would end up that subjects engage in singular activities according to their harmony with stereotypes of their kind. Biological and socio-cultural factors, as well as significant individuals, are among the most important determinants of physical activity among adolescents (Mehdizadeh et al., 2019, Gustafson \& Rhodes, 2006). Based on the gender appropriation of practices, several studies have confirmed the existence of masculine, feminine and gender-appropriate sports (Fontayne, 1999). Several anterior researches studied the relationships between gender and the choice of physical and sports activities in the associative world (Engel, 1994; Fontayne et al., 2000; Guillet et al., 2000; Matteo, 1988). Indeed, the indulging in a sport seems generally related to masculinity but influenced by femininity character when it comes to practicing sports perceived as feminine. It seems also that the choices and rejections of physical activities and sports (P.A.S) in physical education and sports (PES) should be differentially linked to masculinity and femininity or appropriate to both genders (Marsh \& Byrne, 1991). So, are physical education lessons distributed according to gender and physical abilities or other tendency? However, it is important to understand the factors of interest that contribute to sport practice for teenagers in order to improve the effectiveness of physical education programs.

Hypothesis: The choice of Physical Activity Sport (PAS) gender-appropriate offered to students in physical 
education vary consistently according to the respective contributions of male and female and to the interest to discover the practice of a new sports activity.

\section{Method}

\subsection{Participants}

The population consisted of 1326 students from five high schools in Tunisia (724 girls and 602 boys), with an average age of 16.8 years $(\mathrm{SD}=0.92)$ and were all volunteers to complete the questionnaires. The presentation had previously been subject to administrative authorization.

\subsection{Procedure}

The questionnaires were administered in a class, at the end of a course under the joint responsibility of the professor of physical education and sport of the class, a researcher in didactics of PAS and qualified personnel, trained in the questionnaires. The approximate time to answer the questionnaires was approximately 20 minutes.

\subsection{Measures}

A conceptual model of the association between gender sports, inequality, anachronism and gender rule overhauled, as well as difficulty level of each sport practice in our analyses outcome perceptions and interests is presented in Figure 1. Our model was used to understand subs-concepts selection and interactive strategic analysis of the school context of sports practice according to the individual gender difference and logic process of skills development in physical education and sport setting. Physical education domain is a stage on which gender roles are developed in our society.

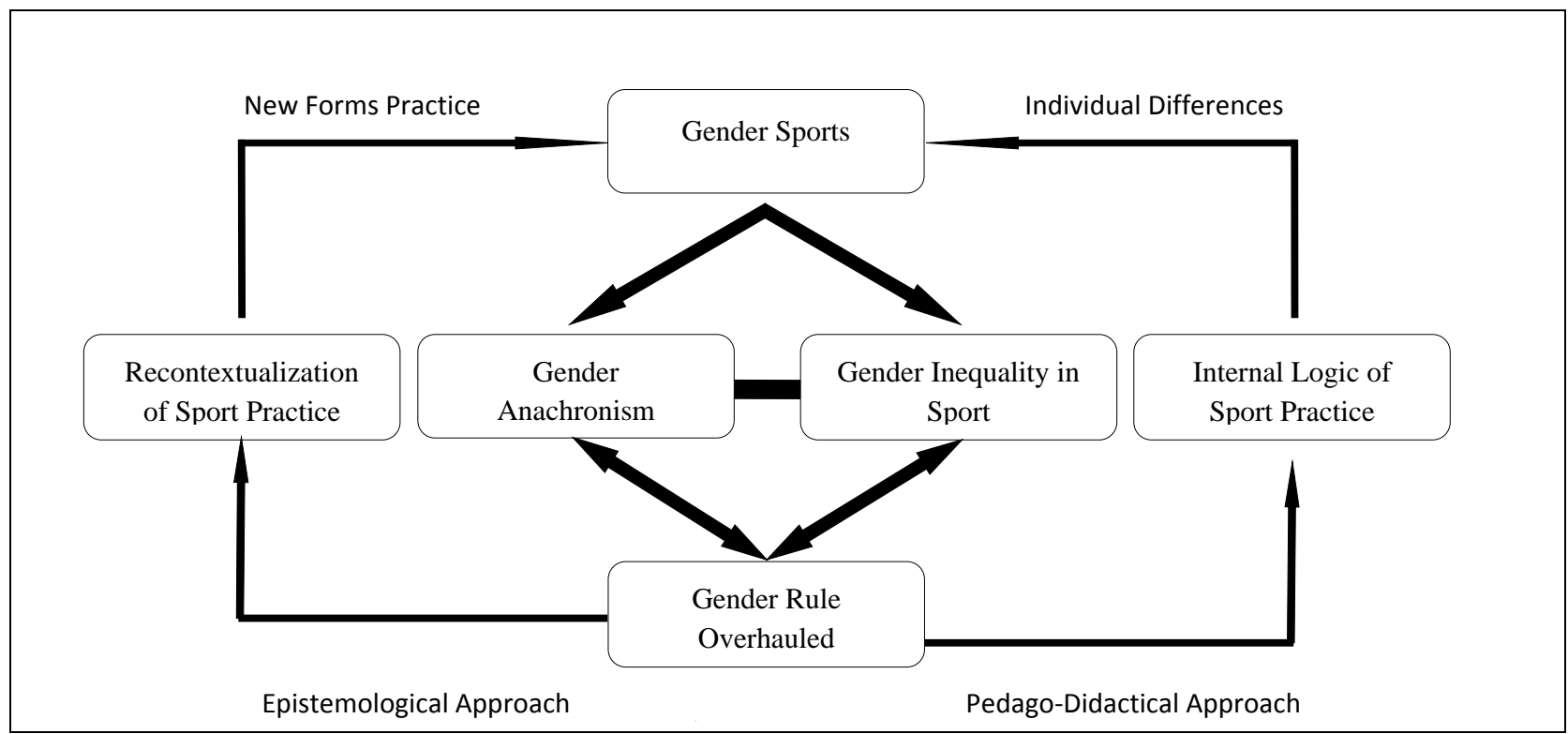

Figure 1. Conceptual Model of Gender Sport Practice

Note: "Gender Sports": it refers to the socially structured relationships between men and women concerning sport for gender equity and personal development; "Gender Anachronism”: it deals with Anachronistic attitude toward sport practices for men and women; "Gender inequality in sport”: female athletes are talented enough to perform well but are they strong enough to reach men capacities in sports?; "Gender Rule Overhauled”: Modifying the form of sport practice to have slight divergence in gender broken down ( e.g. from volleyball to beach volleyball; from pole vaulting to variety jump by pole - high and long jump); Internal Logic of Sport Practice: to ensure a didactic transposition (external and internal transposition) with methods of teaching and learning styles; "Recontextualization of Sport Practice": Curriculum construction and critical analysis of complex tasks in the fields of sport and physical education. 


\subsubsection{Gender Perception of Physical and Sports Activities}

In order to evaluate the sexual perception of P.A.S, we presented a list of 15 sports activities. Its last are chosen on the basis of the programming of PES in high schools and previous work (Fontayne, 1999), the activities were classified as follows:

- Male activities: Basketball, Football, Pole vault, Bodybuilding and Judo;

- Female activities: Gymnastics, Aerobics, Stretching and Rhythmic Gymnastics;

- Activities appropriate to both gender: Athletics, Swimming, Orienteering, Basketball, Tennis and Volleyball.

The interest of these measures for the understanding of the motivation to the practice of certain A.P.S in the school setting has been proven by (Famose, Sarrazin, \& Cury, 1995) and based on the study of Mehdizadeh, et al. (2019) with the evidence process for the validity of the children's attraction to physical activity.

\section{Results}

On the most basic level, being attracted to sports activities means pulling for practice choices whose outcome is impactful on our leisure, performance, health (well-being). Results in (table 1) show that football presents the highest scores among all other sport activities. The second rank is for athletic activities that followed by gymnastic activities in the third place. Table 1 highlights the classification of activities interest by gender. The finding in Table 2 present the mainly appropriate scores and percents for the most important details of sport activities interest for our teenager population.

Table 1. Averages and Standard Deviations of Gender-Specific Perception Scores of Physical Activity and Sport for Boys $(\mathrm{N}=602)$, and Girls $(\mathrm{N}=724)$.

\begin{tabular}{|c|c|c|c|c|}
\hline \multirow[b]{2}{*}{ Sports Activities } & \multicolumn{2}{|c|}{ Girls } & \multicolumn{2}{|c|}{ Boys } \\
\hline & $\mathrm{M}$ & SD & $\mathrm{M}$ & SD \\
\hline \multicolumn{5}{|l|}{ Masculine activities } \\
\hline Football & 2.87 & 1.35 & 6.42 & 1.23 \\
\hline Basket all & 2.57 & 1.65 & 3.54 & 1.24 \\
\hline Body building & 1.09 & .88 & 4.88 & 1.17 \\
\hline Pole vault & 3.61 & 1.32 & 5.28 & 1.02 \\
\hline Judo & 1.21 & 1.06 & 3.92 & 1.31 \\
\hline \multicolumn{5}{|l|}{ Feminine activities } \\
\hline Aerobics & 3.51 & 1.09 & 3.54 & 1.14 \\
\hline Dance & 3.65 & 1.13 & 1.00 & .90 \\
\hline Gymnastic & 6.39 & 1.32 & 5.34 & 1.02 \\
\hline Rhythmic Gymnastics & 5.06 & 1.08 & 2.51 & 1.06 \\
\hline Stretching & 3.27 & 1.04 & 2.40 & .96 \\
\hline \multicolumn{5}{|c|}{ Activities appropriate to both gender } \\
\hline Athletics & 5.36 & 1.06 & 6.32 & .92 \\
\hline Race Orientation & 4.03 & 1.28 & 4.41 & 1.18 \\
\hline Swimming & 5.13 & 1.22 & 4.64 & 1.04 \\
\hline Tennis & 3.88 & 1.21 & 3.53 & .99 \\
\hline Volleyball & 4.19 & .98 & 4.86 & 1.62 \\
\hline
\end{tabular}

Note: $\mathrm{M}$ - mean; SD - standard deviation; $\mathrm{N}$ - number of participants

The results, shown in Table 1, show that this priori classification of physical and sports activities is very similar to the perception of students in our study population. The averages polls for each group of sports activities were treated in the statistical analysis. The alpha coefficients (Cronbach, 1951) are 0.78 for man's activities, 0.86 for women's activities, and 0.79 for activities appropriate to both gender. 
Table 2. Frequency and Percentage Statistics on Attachment to Physical and Sports Activities: Athletics, Pole Vault and Gymnastics

\begin{tabular}{lcccc}
\hline & & Athletics & Pole Vault & Gymnastic \\
\hline N-Total & 1326 & $715(53.92 \%)$ & $326(24.58 \%)$ & $384(28.95 \%)$ \\
Boys & 527 & 350 & 217 & 145 \\
Girls & 660 & 365 & 109 & 239 \\
\hline Athlete & 389 & 240 & 179 & 216 \\
Boys & 225 & 117 & 113 & 86 \\
Girls & 164 & 123 & 66 & 130 \\
\hline Non- Athlete & 937 & 475 & 147 & 58 \\
Boys & & & & 110 \\
Girls & 302 & 233 & 43 & \\
\hline
\end{tabular}

Note: $\mathrm{N}$ - number of participants; \% - percentage

Statistics of the choice and rejection of physical and sports activities are highlighted. On the one hand, the variance explained in the choice of male activities is $64 \%$. Whereas, the variance ration relating to the choice of female activities is $43 \%$. Finely, the total variance explained in choosing the appropriate activities for both gender is $25 \%$. On the other hand, the variances explained in the rejection of physical and sports activities are respectively (23\%, 35\% and $12 \%)$.

\section{Discussion}

The main purpose of this work was to evaluate differential attraction to physical activity. It is important to note that the gender of the subjects classifies the frequency, the modalities, and consequently the type of sport practice. In particular, we questioned the influence of gender on the appropriation of physical and sport activities. Data analysis confirms the effect of gender on the value given to an activity. Based on the work of Bem (1981), students with powerful gender identity value activities that are appropriate to their identity, and avoid activities that are not harmonious with it. In addition, several studies have examined and identified several correlates of psychosocial and environmental physical activity among teenagers (Seabra et al., 2014; Ferreira et al., 2007; Sallis, Prochaska, \& Taylor, 2000).

The results show that (24.58\%) boys and girls subjects chose pole vault as an activity desired to be taught in physical education as much as a male activity. And comparably, gymnastics is been wanted activity for both genres (24.58\%) as much as it belongs to the category of women's activities. In addition, pole vaulting is an athletic activity. And athletics belongs to activities appropriate to both sexes. We can therefore see that the subjects who choose the most appropriate activities for both genders are interested in athletics (53.92\%). Also, with regard to the effect of sex type of physical and sports activities the results are in line with what was expected. Sexually-typed subjects (e.g., boys and girls) tend to practice proper activities with their identity. In this way, when they play sports, there are more boys than girls to practice male sports activities, whereas the number of girls is more important than boys to practice female sports activities.

In the case of sports practice, several authors suggest that it is the scores of subjects on the masculine sub-scale that determine the different patterns of behavior (Butcher, 1989; Gill, 1992). We might try to point out, as has already been done with regard to the dominating influence of gender on the subject's school curriculum through different motivational variables (Derbali et al., 2017c, 2018b; Duru-Bellat, 1995; Eccles, 1987), that the same mechanisms can be evoked for gender in particular settings such as high-level sporting practice, or the compulsory practice of physical and sports education. Campbell and Gillapsy (1997) already pointed out that masculinity and femininity are essentially orthogonal, the correlation may vary with the study population even if the constructs themselves remain invariant. Indeed, we can put forward the problem of sports participation in its entirety (e.g., sports versus non-sports), and through the hierarchical model presented above in Figure 1. In line with the finding, the inequality within sport physical self-perception will continue (Derbali et al., 2015a; Trolan, 2013). In our conceptual model (see Figure 1), gender sports refer to the socially structured relationships between girl and boys concerning sport for gender equity and individual maturity. Beyond, gender anachronism tends with a regularly anachronistic attitude toward sport practices for boys and girls. The gender equality in sports has always been a controversial topic. Even female athletes are 
talented enough to perform well, are they strong enough to reach men capacities in sports? That's why gender inequality in sport remains obsession within females and equality still a recognized issue. So, as an effective strategy, to attribute a gender rule overhauled: might modify the form and rule of sport practice to have slight divergence in gender broken down (e.g. from volleyball to beach volleyball; from pole vaulting to jump in different ways: jump forward and up; with and without pole; etc.). Indeed, the necessity of physical education courses in curriculum request an interactive strategy with physical activity attraction and teenager gender. So, for effective practice an internal logic of sport practice should be established throw a didactic transposition (external and internal transposition) and applied with pedagogical methods of teaching and learning styles. By recontextualization of sport practice with epistemological approach with innovative tendency, we can have a spiral curriculum construction and critical analysis of complex tasks in physical education domain (Derbali et al., 2017a; Derbali \& Elloumi, 2014).

Accordingly, the results allow us to consider that the three conditions of masculinity, femininity, and multiple dimensions of self-concept which reach to support the validity of the model (Marsh \& Byrne, 1991; Derbali, 2010) are completely respected. The gender image (Vallerand, 1994) is therefore likely to influence other socio-cognitive regulators such as the expectation of success, the choice of the activity, and the performed performances. Expectations are a function of the perceived competence related to gender focused on teacher strategy to enhance motor skills (Derbali et al., 2018c). This finding is typically confirmed by (Bem, 1981). While in terms of perceived difficulty, sport culture and adolescents' behavior (Boyes et al., 2017; Derbali et al., 2015a), the combination of high physical and social engagement was associated with the highest risk for boys, whereas for girls a strong social commitment was associated with the highest risk. In addition, subjects are more interested in activities in which they perform and fit his motivation profile as a psychological variable (Gumbo et al., 2017; Derbali et al., 2015b; Rintaugu et al., 2012) with providing the necessary equipment and facilities to enable the use of a variety of strategies and also enhance effectiveness of several pedagogic methods by interactive strategy. In other words, it is interesting to find other explanations than the gender-related self-image and prediction of self-efficacy in physical education (Derbali et al., 2009, 2008), to explain the repugnance and the desire for these activities (e.g., the perceived skill specific to this activity, the perceived difficulty, etc.). Furthermore, in Human Development Report (2013), equality of positions in society is an important issue in specific areas that need to be focused on to support development more equitably, including with regard to the gender dimension; citizen participation, including youth (HDR, 2013).

\section{Conclusion}

As a conclusion, we will therefore say that the data presented in this study are in line with the model of differential attraction to physical activity and sport according to gender. And since pole vaulting activity is the main element in our work, it would be interesting to include the dimensions not only measuring the perception difficulty but also the strategy of educative practice throw innovative spiral curriculum. As well as the masculine and feminine gender-based self-image in a larger model of accepting achievement, not only to prescribe the student's commitment to pole vaulting activity, but also the abilities to develop in practice of all sports. It could be considered deeply dependent on cognitive development, motor, and self-concept integrating many other dimensions. In our opinion, the study of individual differences in behavior and developmental reasons in the field of physical and sport activities in PES can be done by taking into account the gender, cultural and socio-historical contexts in which the practice of gymnastics, athletics and pole vaulting, is developing in a dynamic strategy and interactionist perspective.

\section{References}

Bem, S. L. (1981). Gender schema theory: A cognitive account of sex-typing. Psychological Review, 88, 354-364. https://doi.org/10.1037/0033-295X.88.4.354

Boyesa, R., O’Sullivana, D. E., Brooke L., McIsaaca, M., \& Picketta, W. (2017). Gender-specific associations between involvement in team sport culture and Canadian adolescents' substance-use behavior. SSM Population Health, 3, 663-673. http://dx.doi.org/10.1016/j.ssmph.2017.08.006

Burton, L. J. (2015). Underrepresentation of women in sport leadership: A review of research. Sport Management Review, 18, 155-165. http://dx.doi.org/10.1016/j.smr.2014.02.004

Butcher, J. E. (1989). Adolescent girl's sex role development : Relationship with sport participation, self-esteem, and age at menarche. Sex Roles, 20, 575-593. https://doi.org/10.1007/BF00288202 
Campbell, T., \& Gillapsy, J-A. (1997). The factor structure of the Bem Sex-Role Inventory (BSRI): Confirmatory Analysis of long and short forms. Educational and Psychological Measurement, 57(1), 118-124. https://doi.org/10.1177/0013164497057001008

Cronbach, L. (1951). Coefficient alpha and internal strucure of test. Psychometrika, 16, 296-334. https://doi.org/10.1007/BF02310555

Derbali, C. (2010). Perception, Motivation et Autonomie Concept de soi et apprentissage: Apprentissage en Éducation Physique. Éditions Universitaire Européenne -Nº ISBN 10: 6131533989/ISBN 13: 9786131533983

Derbali, C., \& Elloumi, A. (2014). Reflection on a Didactic Transposition of Pole Vaulting: From a Performance Sport to a School Practice in Physical Education and Sport. Acts of 13th International Sport Sciences Congress. In Proceeding Book (pp.136-137). www.Sporbilim.Com/Userfiles/File/13thisscscientificprogram.Pdf

Derbali, C., \& Naceur, A. (2009). Relationships between physical self-perception and physical self-determination: prediction of physical self-efficacy. In "Cognition, Emotion \& Motivation: Percept - Concept Decision ...Applications to learning activities”. ISBN 978-9973-13009-9.

Derbali, C., Ben Jannet, Z., \& Elloumi, A. (2015b). Physical self-perception and sport's activity applied in physical education context: The self-efficacy of achievement performance. International Journal of Advanced Sport Sciences Research, 3(1), 482-497.

Derbali, C., Elloumi, A., \& Matoussi, F. (2015a). Didactics of Physical Education: The Case of Motivational students Profiles in Pole Vaulting Performance. Creative Education, 6(12), 1349-1359. http://dx.doi.org/10.4236/ce.2015.612136

Derbali, C., Elloumi, A., \& Matoussi, F. (2017a). The Need to Learn according to Psycho-Didactic Approach: Self-Determination and Student's Performance in Physical Education Realm. Creative Education, 8, 1155-1171. https://doi.org/10.4236/ce.2017.87083

Derbali, C., Elloumi, A., \& Matoussi, F. (2017b). Reflections and Conceptions Analysis of the Neosphere's Actors on Teaching Pole Vault Activity throw Physical Education Program. International Research Journal of Curriculum and Pedagogy, 3(2), 52-58.

Derbali, C., Elloumi, A., \& Matoussi, F. (2018c). Teaching Strategies to Enhance Motor Skills Learning for Groups of Students: The Effects of Verbal and Visual Feedback on Performance in Pole Vault Practice. Journal of Physical Education \& Health, 7(12), 11-28.

Derbali, C., Matoussi, F., \& Elloumi, A. (2017c). Motivational Climate and Skills Development in Physical Education: A Pilot Study Examining Physical Activity Behavior in an Educational Environment. Journal of Information Research and Review, 4(12), 4756-4763.

Derbali, C., Matoussi, F., \& Elloumi, A. (2018b). Curriculum Method Grounded on Didactic Engineering to Expertise Physical Education Program Proposal. Journal of Education and Practice, 31(9), 49-59.

Derbali, C., Naceur, A., \& Masmoudi, S. (2008). Effet du Concept de soi sur le processus d'apprentissage d'une activité sportive: cas du triple saut. In A., Naceur \& S., Masmoudi (Eds.), Cognition, Emotion \& Motivation : Intégrer ... Mieux expliquer la performance. Éditions CNIPRE, Tunis ISBN 9973-13-011-2.

Duru-Bellat, M. (1995). Filles et garçons à l'école, approches sociologiques et psychosociales. 2e Partie : La construction scolaire des différences entre les sexes. Revue Française de Pédagogie, 110, 75-109. https://doi.org/10.3406/rfp.1995.1242

Eccles, J. S. (1987). Gender roles and women's achievement-related decisions. Psychology of Women Quaterly, 11, 135-172. https://doi.org/10.1111/j.1471-6402.1987.tb00781.x

Engel, A. (1994). Sex Roles and gender stereotyping in young women's participation in sport. Special features: Doing by degrees: Feminist undergraduate dissertations. Feminism and Psychology, 4, 439-448. https://doi.org/10.1177/0959353594043016

Famose, J. P., Sarrazin, P. H., \& Cury, F. (1995). Apprentissage moteur et buts d'accomplissement. In: J. Bertsch, et C. Le Scanff. Apprentissage moteur et conditions d'apprentissages Paris, PUF: 89-152.

Ferreira, I., Van Der Horst, K., Wendel-Vos, W., Kremers, S., Van Lenthe, F. J., \& Brug, J. (2007). Environmental correlates of physical activity in youth-a review and update. Obesity Reviews, 8(2), 129-154. https://doi.org/10.1111/j.1467-789X.2006.00264.x 
Fontayne, P. (1999). Motivation et activites physiques et sportives : influence du sexe et du genre sur la pratique du sport et de l'education physique. Thèse en Sciences et Techniques des Activites Physiques et Sportives, non-publiee, Universite Paris-Sud Orsay.

Fontayne, P., Sarrazin P., \& Famose, J. P. (2000). The Bem Sex-Role Inventory: Validation of a short-version for French teenagers. European Review of Applied Psychology, 50(4), 405-416.

Gill, D. L. (1992). Gender and sport behavior. In T. Horn (Ed.), Advances in sport psychology (pp. 143-160). Champaign, IL: Human Kinetics.

Guillet, E., Sarrazin, P., \& Fontayne, P. (2000). If it is in contradiction with my gender-role, I'll stop!. Introducing survival analysis to study the effects of gender typing on the time of withdrawal from sport practice; a 3-year study. European Review of Applied Psychology, 50(4), 417-421.

Gumbo, S., Magonde, S., \& Nhamo, E. (2017). Teaching Strategies Employed by Physical Education Teachers in Gokwe North Primary Schools. International Journal of Sport, Exercise and Health Research, 1(2), 61-65. https://doi.org/10.4236/ce.2017.87083

Human Development Report. (2013). United Nations Development Programme. New York: U.S.A.

Marsh H. W., \& Byrne B. M. (1991). Differentiated additive androgyny model: Relations between masculinity, femininity and multiple dimensions of self-concept. Journal of Personality and Social Psychology, 61, 811-828. https://doi.org/10.1037/0022-3514.61.5.811

Matteo, S. (1988). The effect of gender-schematic processing on decisions about sex in appropriate sport behavior. Sex Roles, 18(1/2), 41-58. https://doi.org/10.1007/BF00288016

Mehdizadeh, A. et al. (2019). Evidence for the Validity of the Children's Attraction to Physical Activity (CAPA) Scale in Iranian Preschool Children. Journal of Pediatric Nursing, 44, 52-57. https://doi.org/10.1016/j.pedn.2018.10.021

Rintaugu, E. G., \& Ngetich, E. D. K. (2012). Motivational gender differences in sport and exercise participation among university sport science students. Journal of Physical Education and Sport (JPES), 12(2), 180-187.

Sallis, J. F., Prochaska, J. J., \& Taylor,W. C. (2000). A review of correlates of physical activity of children and adolescents. Medicine \& Science in Sports \& Exercise, 32(5), 963-975. https://doi.org/10.1097/00005768-200005000-00014

Seabra, A. C., Malina, R. M., Parker, M., Seabra, A., Brustad, R., Maia, J. A., \& Fonseca, A. M. (2014). Validation and factorial invariance of children's attraction to physical activity (CAPA) scale in Portugal. European Journal of Sport Science, 14(4), 384-391. https://doi.org/10.1080/17461391.2013.828777

Trolan, E. J. (2013). The impact of the media on gender inequality within sport. Procedia - Social and Behavioral Sciences, 91, 215-227. https://doi.org/0.1016/j.sbspro.2013.08.420 